\title{
Article \\ Identification of Predictive Biomarkers of Response to HSP90 Inhibitors in Lung Adenocarcinoma
}

\author{
Ángela Marrugal ${ }^{1}$, Irene Ferrer 1,2, David Gómez-Sánchez ${ }^{1,2}$, Álvaro Quintanal-Villalonga ${ }^{3}$, \\ María Dolores Pastor ${ }^{4}$, Laura Ojeda ${ }^{1}$, Luis Paz-Ares ${ }^{1,2,5,6, *,+}$ and Sonia Molina-Pinelo ${ }^{2,4, *,+}$ (D)
}

1 H12O-CNIO Lung Cancer Clinical Research Unit, Instituto de Investigación Hospital 12 de Octubre \& Centro Nacional de Investigaciones Oncológicas (CNIO), 28029 Madrid, Spain; ammarrugal.imas12@h12o.es (Á.M.); iferrer@ext.cnio.es (I.F.); dags.imas12@h12o.es (D.G.-S.); lauojeda@ucm.es (L.O.)

2 CIBERONC, Respiratory Tract Tumors Program, 28029 Madrid, Spain

3 Program in Molecular Pharmacology, Memorial Sloan Kettering Cancer Center, New York, NY 10065, USA; quintaa1@mskcc.org

4 Institute of Biomedicine of Seville (IBIS) (HUVR, CSIC, Universidad de Sevilla), 41013 Sevilla, Spain; mpastor-ibis@us.es

5 Medical Oncology Department, Hospital Universitario Doce de Octubre, 28041 Madrid, Spain

6 Medical School, Universidad Complutense, 28040 Madrid, Spain

* Correspondence: lpazaresr@seom.org (L.P.-A.); smolina-ibis@us.es (S.M.-P.)

+ These authors contributed equally to this work.

\section{check for} updates

Citation: Marrugal, Á.; Ferrer, I.; Gómez-Sánchez, D.;

Quintanal-Villalonga, Á.; Pastor,

M.D.; Ojeda, L.; Paz-Ares, L.;

Molina-Pinelo, S. Identification of

Predictive Biomarkers of Response to HSP90 Inhibitors in Lung

Adenocarcinoma. Int. J. Mol. Sci. 2021, 22, 2538. https://doi.org/ 10.3390/ijms22052538

Academic Editor: Nikolas Nikolaidis

Received: 29 January 2021

Accepted: 27 February 2021

Published: 3 March 2021

Publisher's Note: MDPI stays neutral with regard to jurisdictional claims in published maps and institutional affiliations.

Copyright: (c) 2021 by the authors. Licensee MDPI, Basel, Switzerland. This article is an open access article distributed under the terms and conditions of the Creative Commons Attribution (CC BY) license (https:/ / creativecommons.org/licenses/by/ $4.0 /)$.
Abstract: Heat shock protein 90 (HSP90) plays an essential role in lung adenocarcinoma, acting as a key chaperone involved in the correct functioning of numerous highly relevant protein drivers of this disease. To this end, HSP90 inhibitors have emerged as promising therapeutic strategies, even though responses to them have been limited to date. Given the need to maximize treatment efficacy, the objective of this study was to use isobaric tags for relative and absolute quantitation (iTRAQ)based proteomic techniques to identify proteins in human lung adenocarcinoma cell lines whose basal abundances were correlated with response to HSP90 inhibitors (geldanamycin and radicicol derivatives). From the protein profiles identified according to response, the relationship between lactate dehydrogenase B (LDHB) and DNA topoisomerase 1 (TOP1) with respect to sensitivity and resistance, respectively, to geldanamycin derivatives is noteworthy. Likewise, rhotekin (RTKN) and decaprenyl diphosphate synthase subunit 2 (PDSS2) were correlated with sensitivity and resistance to radicicol derivatives. We also identified a relationship between resistance to HSP90 inhibition and the p53 pathway by glucose deprivation. In contrast, arginine biosynthesis was correlated with sensitivity to HSP90 inhibitors. Further study of these outcomes could enable the development of strategies to improve the clinical efficacy of HSP90 inhibition in patients with lung adenocarcinoma.

Keywords: HSP90 inhibitors; protein biomarkers predictive of response; lung adenocarcinoma

\section{Introduction}

Heat shock protein 90 (HSP90) is one of the most abundant and important heat shock proteins (HSPs) [1], functioning as a chaperone involved in the maturation, stabilization, and activation of more than 300 so-called "client proteins" [2,3]. Remarkably, most of HSP90's client proteins are oncoproteins with crucial roles in different hallmarks of cancer $[4,5]$. For this reason, HSP90 is also known as the "cancer chaperone", making it an important antitumor target, particularly in tumors such as lung cancer where HSP90 client proteins act as oncodrivers [6-8].

Lung cancer is the leading cause of cancer death in both men and women worldwide [9]. Concerning lung adenocarcinoma, the main non-small-cell lung cancer (NSCLC) subtype, which also represents approximately $50 \%$ of the total lung cancer cases, the fact that it can be driven by different genetic alterations is remarkable. Interestingly, the resulting proteins of many oncodrivers, such as epidermal growth factor receptor (EGFR) [10], 
Erb-B2 receptor tyrosine kinase 2 (ERBB2) [11], MET proto-oncogene, receptor tyrosine kinase (MET) [12], B-Raf proto-oncogene, serine/threonine kinase (BRAF) [13], or the echinoderm microtubule-associated protein-like (EML4)-anaplastic lymphoma kinase (ALK) fusion protein [14], are clients of HSP90. Nevertheless, the instability of these drivers and, as a consequence, their degradation via the targeted inhibition of HSP90 lead to a loss of viability of tumor cells. Consequently, elevated HSP90 expression has been correlated with a poorer clinical prognosis, such as resistance to chemotherapy and radiotherapy $[15,16]$. HSP90 inhibitors have shown antitumoral activity potential in preclinical studies and clinical trials in the treatment of NSCLC [17]. In addition, HSP90 inhibitors have been proposed to act as chemosensitizers [18] and radiosensitizers [19] and prevent acquired resistance to targeted therapies $[20,21]$.

Some of the most promising HSP90 inhibitors have been the geldanamycin derivatives tanespimycin (17-AAG) and retaspimycin hydrochloride (IPI-504), as well as the radicicol analogs ganetespib (STA-9090) and luminespib (AUY-922) [22]. These inhibitors all act by blocking HSP90's ATP binding site, which leads to proteasomal client degradation [23,24]. They have been widely evaluated in clinical trials with lung cancer patients and have shown encouraging results [25-30], specifically in those studies where the patients were molecularly stratified, such as lung adenocarcinoma patients with mutated EGFR and translocated ALK $[25,27,28,31]$. However, HSP90 inhibition as a treatment for lung cancer is still limited due to moderate efficacy outcomes, emergence of resistance, and early recurrence $[17,32]$. Recent research has focused on studying proteomic alterations produced at the cellular level after HSP90 inhibition as well as the physiological consequences of this blockade $[33,34]$. In this sense, previous results from our research group identified putative biomarkers of the HSP90 inhibition response in lung adenocarcinoma; these included eukaryotic translation initiation factor 3 subunit I (EIF3I) and transketolase, among others. In addition, it was shown that altered proteomic profiles after HSP90 inhibition affect energy production as well as metabolic and apoptotic pathways [35]. In this context, the complex interactome of HSP90 and the elevated number of cellular processes in which this chaperone is involved have made it commonplace for proteomic tools to be used to study HSP90 and its inhibition [36]. However, predictive biomarkers to identify which patients will respond positively (or not) to treatment have not yet been described, this being an essential condition for the therapeutic efficacy of HSP90 inhibitors to be optimized [32]. For these reasons, the main objective of our study was to use iTRAQ-based proteomics techniques to comprehensively characterize the proteomic profile associated with sensitivity and resistance to HSP90 inhibitors in human lung adenocarcinoma cell lines. Our findings are potentially important for improving therapeutic strategies to effectively treat this disease.

\section{Results}

2.1. Determination of Proteomic Profiles Correlated with HSP90 Inhibitor Sensitivity or Resistance

iTRAQ protein quantitation coupled to mass spectrometry (NanoLC-MS/MS, Thermo Fisher Scientific, Waltham, Massachusetts, United States) was employed to predict sensitivity or resistance to HSP90 inhibitors by means of proteomic profiling of a panel of lung adenocarcinoma cell lines. Prior to treatment, the cell lines were profiled as mentioned and the basal abundance of proteins was calculated. An average of around 5000 proteins per cell line was identified (Figure 1). 


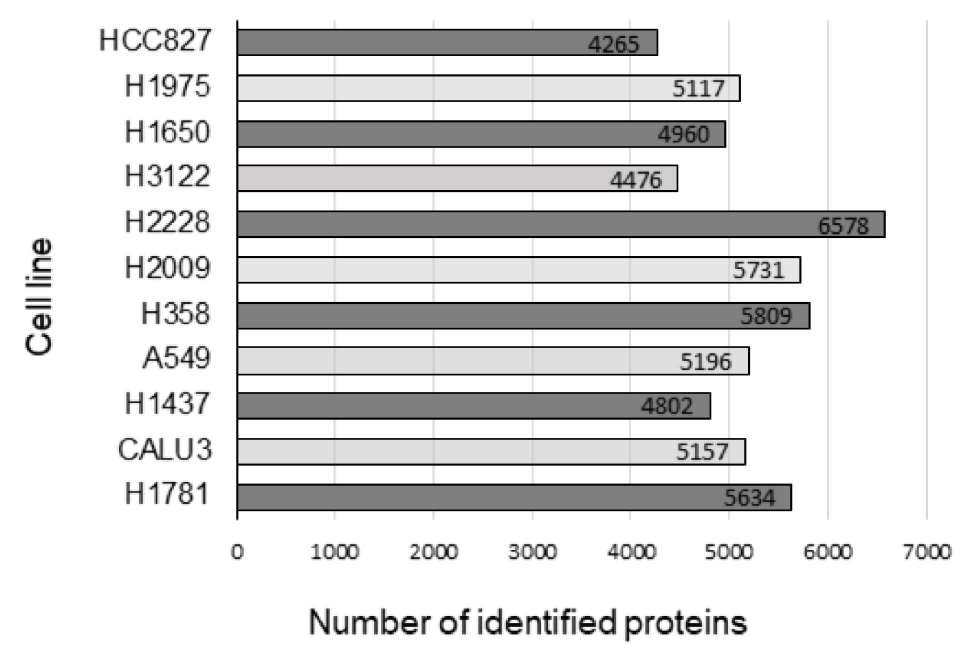

Figure 1. Number of proteins per cell line identified by iTRAQ and mass spectrometry analysis.

To evaluate the efficiency of the response to HSP90 inhibition, the $\mathrm{IC}_{50}$ values for four HSP90 inhibitors were determined in our cell line panel. Table 1 shows IC $_{50}$ values for geldanamycin derivatives (17-AAG and IPI-504) and radicicol derivatives (STA-9090 and AUY-922). The $\mathrm{IC}_{50}$ value was used to select the three cell lines most sensitive and resistant to each HSP90 inhibitor studied. In response to 17-AAG, cell lines H1975, H1437, and $\mathrm{H} 1650$ showed the lowest $\mathrm{IC}_{50}$ values (ranging from 1.258 to $6.555 \mathrm{nM}$ ); in contrast, HCC827, H2009, and Calu-3 showed the highest values ( $\mathrm{IC}_{50}$ values between 26.255 and $87.733 \mathrm{nM}$ ). For the other geldanamycin derivative, IPI-504, the most sensitive lines were $\mathrm{H} 1437\left(\mathrm{IC}_{50}: 3.473 \mathrm{nM}\right), \mathrm{H} 1650\left(\mathrm{IC}_{50}: 3.764 \mathrm{nM}\right)$, and $\mathrm{H} 358\left(\mathrm{IC}_{50}: 4.662 \mathrm{nM}\right)$, while the most resistant were $\mathrm{H} 2009$, Calu-3, and $\mathrm{H} 2228$ ( $\mathrm{IC}_{50}$ : 33.833, 43.295, and $46.340 \mathrm{nM}$, respectively). In response to the radicicol derivative STA-9090, the lowest IC $_{50}$ values were found in cell lines H2228, H2009, and H1975 (range: 4.131-4.739 nM), and the highest values were found in $\mathrm{H} 3122\left(\mathrm{IC}_{50}: 7.991 \mathrm{nM}\right), \mathrm{H} 1781\left(\mathrm{IC}_{50}: 9.954 \mathrm{nM}\right)$, and Calu-3 (IC $\left.\mathrm{I}_{50}: 18.445\right)$. In response to AUY-922 treatment, H1650, H2009, and H1975 were the most sensitive cell lines (IC 50 values ranging from 1.472 to $2.595 \mathrm{nM}$ ), while H1781, A549, and Calu-3 were the most resistant $\left(\mathrm{IC}_{50}\right.$ values between 23.787 and $\left.1740.91 \mathrm{nM}\right)$.

Table 1. $\mathrm{IC}_{50}$ values for geldanamycin and radicicol analogs.

\begin{tabular}{ccccc}
\hline \multirow{2}{*}{ Cell Line } & \multicolumn{2}{c}{ Geldanamycin Derivatives } & \multicolumn{2}{c}{ Radicicol Derivatives } \\
\cline { 2 - 5 } & $\begin{array}{c}\text { IC }_{\mathbf{5 0}} \mathbf{1 7 - A A G} \\
\text { (nM) }\end{array}$ & $\begin{array}{c}\text { IC }_{\mathbf{5 0}} \text { IPI-504 } \\
\text { (nM) }\end{array}$ & $\begin{array}{c}\text { IC }_{\mathbf{5 0}} \text { STA-9090 } \\
\text { (nM) }\end{array}$ & $\begin{array}{c}\text { IC }_{\mathbf{5 0}} \text { AUY-922 } \\
\text { (nM) }\end{array}$ \\
\hline HCC827 & 26.255 & 17.145 & 5.138 & 4.167 \\
H1975 & 1.258 & 12.750 & 4.739 & 2.595 \\
H1650 & 6.554 & 3.764 & 5.659 & 1.472 \\
H3122 & 26.165 & 28.371 & 7.991 & 9.110 \\
H2228 & 10.888 & 46.340 & 4.131 & 4.488 \\
H2009 & 43.198 & 33.833 & 4.659 & 2.477 \\
H358 & 13.066 & 4.662 & 7.740 & 8.105 \\
A549 & 16.296 & 19.492 & 6.310 & 30.733 \\
H1437 & 3.708 & 3.473 & 6.794 & 2.814 \\
CALU-3 & 87.733 & 43.295 & 18.445 & 1740.91 \\
H1781 & 12.345 & 30.975 & 9.954 & 23.787 \\
\hline
\end{tabular}

Our next step was to identify proteins commonly appearing in cell lines that were more sensitive or more resistant to the different treatments. Spearman's rank correlation coefficient was then used to identify whether the basal abundances of these common proteins were correlated with the $\mathrm{IC}_{50}$ value of each inhibitor used in all the studied cell 
lines. Based on this criterion, for the geldanamycin derivatives 17-AAG and IPI-504, 27 and 1664 proteins, respectively, were related to sensitivity, while 171 and 1772 , respectively, were related to resistance. Conversely, for the radicicol analogs STA-9090 and AUY-922, 51 and 1294 proteins, respectively, were correlated with sensitivity, while 21 and 1257, respectively, were correlated with resistance (Table 2). Notably, more proteins were related to sensitivity to radicicol derivatives, while more proteins were related to resistance to geldanamycin derivatives. Based on these differences, the study was continued according to the family of HSP90 inhibitors used.

Table 2. Number of proteins significantly correlated with sensitivity or resistance to the studied HSP90 inhibitors.

\begin{tabular}{cccc}
\hline \multirow{2}{*}{ Treatment } & \multirow{2}{*}{ Response } & \multicolumn{2}{c}{ Number of Response-Related Proteins } \\
\cline { 3 - 4 } & & Detected & Significant \\
\hline \multirow{2}{*}{ 17-AAG } & Sensitivity & 3724 & 27 \\
& Resistance & 3607 & 171 \\
\hline \multirow{2}{*}{ IPI-504 } & Sensitivity & 3898 & 1664 \\
& Resistance & 4395 & 1772 \\
\hline \multirow{2}{*}{ STA-9090 } & Sensitivity & 4497 & 51 \\
& Resistance & 3704 & 121 \\
\hline \multirow{2}{*}{ AUY-922 } & Sensitivity & 4149 & 1257 \\
& Resistance & 3934 & \\
\hline
\end{tabular}

2.2. Identification of Candidate Biomarkers for Predicting Sensitivity to HSP90 Inhibitors in Lung Adenocarcinoma Cell Lines

Proteins whose basal abundances were correlated significantly with sensitivity to the different HSP90 inhibitor families were identified.

Focusing on the geldanamycin derivatives, a Venn diagram was built to determine the proteins associated with lower $\mathrm{IC}_{50}$ values for these HSP90 inhibitors (Figure 2A). We generated proteomic profiles for each drug, with 15 proteins expressed in only those cell lines with the highest sensitivity to 17-AAG and with 1652 proteins in the case of cell lines with high sensitivity to IPI-504 (Table S1). Additionally, both drugs shared 12 proteins in common that were associated with sensitivity to inhibition. Specifically, the 12 identified proteins were adenylate kinase 2 (AK2), ATP synthase subunit delta (ATP5D), disks large-associated protein 5 (DLGAP5), glycosylphosphatidylinositol anchor attachment 1 protein (GPAA1), guanine nucleotide-binding protein $G(k)$ subunit alpha (GNAI3), lactate dehydrogenase B (LDHB), mitochondrial ribosomal protein S23 (MRPS23), polypyrimidine tract-binding protein 1 and 3 (PTBP1/3), pyruvate dehydrogenase protein X component (PDHX), ubiquitin-fold modifier 1 (UFM1), and zinc finger AN1-type containing 1 (ZFAND1) (Table S2). By mapping the protein-protein interactions of all common proteins associated with sensitivity to geldanamycin derivatives, we identified an interaction between AK2, ATP5D, and PDHX that is also associated with de novo purine synthesis (Figure 2B). 
A

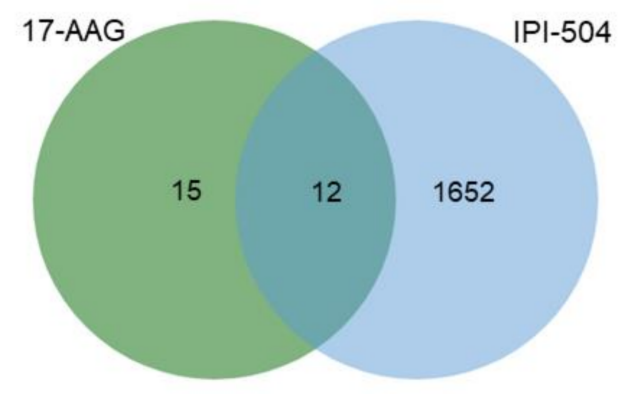

B

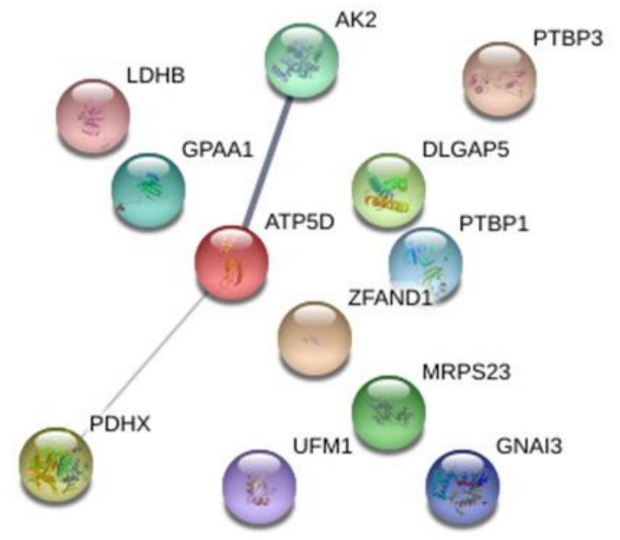

Figure 2. Study of proteins related to sensitivity to geldanamycin derivatives. (A) Venn diagram showing the overlap of proteins associated with a more sensitive response to 17-AAG and IPI-504 inhibitors. The analysis of shared proteins following geldanamycin treatments was performed with STRING software (https://string-db.org/), which identified (B) interactions between AK2, ATP5D, and PDHX proteins.

Concerning radicicol analogs, rhotekin (RTKN), tubulin beta-2A chain (TUBB2A), and tubulin beta-6 chain (TUBB6) were identified as proteins related to sensitivity to both drugs tested (Figure 3A and Table S3). Figure 3B shows how, of all of the proteins identified, TUBB2A and TUBB6 were the only ones that interacted; this interaction is also associated with cytoskeletal regulation by the Rho GTPases pathway. In addition, we identified 48 proteins expressed only in cell lines with a high sensitivity to STA9090, while 1291 proteins were expressed only in cell lines sensitive to AUY-992 (Figure 3A and Table S1).

A

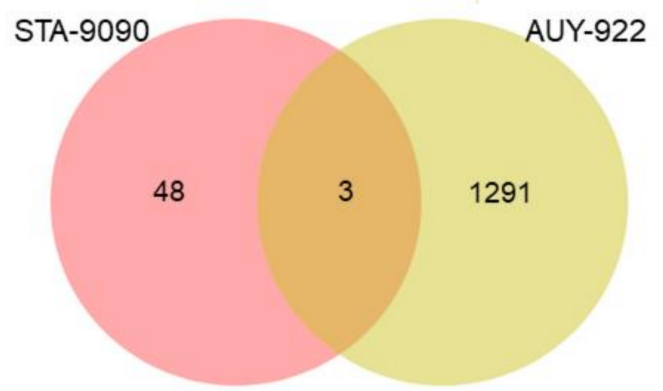

B

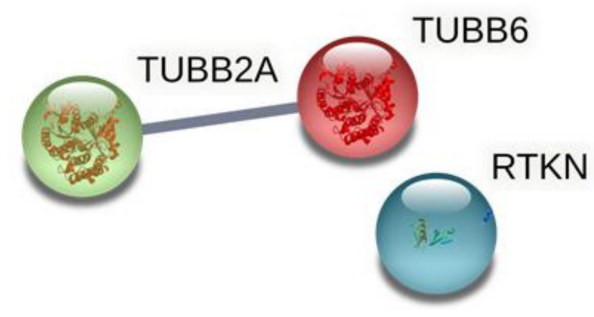

Figure 3. Analysis of proteins associated with sensitivity to radicicol derivatives. (A) Common proteins related to optimal response to STA-9090 and AUY-922 as well as those specific to each HPS90 inhibitor are shown in a Venn diagram. (B) STRING software was used to determine interactions between common proteins related to sensitivity to geldanamycin treatments.

\subsection{Detection of Potential Predictive Biomarkers of Resistance to HSP90 Inhibition in Lung Adenocarcinoma Cell Lines}

Proteins whose pretreatment expression was significantly correlated with a lack of response to each HSP90 inhibitor family were isolated and depicted in Venn diagram form (Figure 4). 
A

\section{Geldanamycin derivatives}

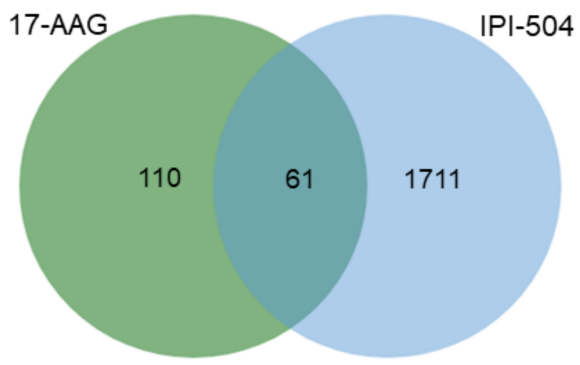

B

\section{Radicicol derivatives}

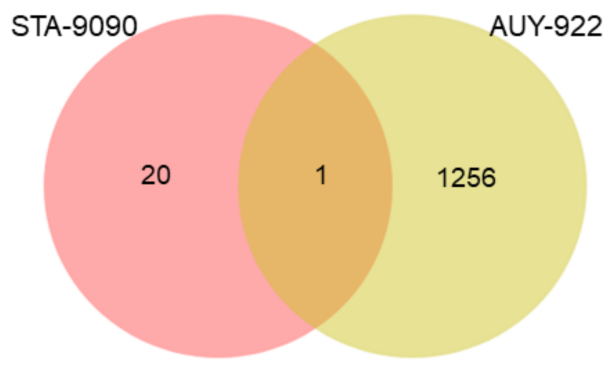

Figure 4. Venn diagrams showing the number of proteins related to resistance to specific geldanamycin (A) or radicicol (B) derivatives and overlap common to each HSP90 inhibitor family.

The 61 proteins related to resistance to geldanamycin derivatives (Figure $4 \mathrm{~A}$ ) are presented in Table 3.

Table 3. Proteins related to a shared resistance to 17-AAG and IPI-504.

\begin{tabular}{|c|c|c|}
\hline Protein Name & UniProt $^{1}$ & Gene $^{2}$ \\
\hline Spliceosome RNA helicase DDX39B & Q13838 & $D D X 39 B$ \\
\hline $26 \mathrm{~S}$ proteasome non-ATPase regulatory subunit 7 & P51665 & PSMD7 \\
\hline 3-hydroxyisobutyryl-CoA hydrolase, mitochondrial & Q6NVY1 & $\mathrm{HIBCH}$ \\
\hline $5^{\prime}\left(3^{\prime}\right)$-deoxyribonucleotidase, cytosolic type & Q8TCD5 & NT5C \\
\hline $5^{\prime}$-AMP-activated protein kinase catalytic subunit alpha-1 & Q13131 & PRKAA1 \\
\hline $5^{\prime}$-nucleotidase domain containing 1 & Q5TFE4 & NT5DC1 \\
\hline Acyl-coenzyme A thioesterase 13 & Q9NPJ3 & ACOT13 \\
\hline Acylglycerol kinase, mitochondrial & Q53H12 & $A G K$ \\
\hline Ankyrin repeat and LEM domain-containing protein 2 & Q86XL3 & ANKLE2 \\
\hline ATP-binding cassette sub-family D member 3 & P28288 & $A B C D 3$ \\
\hline Cleavage stimulation factor subunit 2 tau variant & Q9H0L4 & CSTF2T \\
\hline Coiled-coil domain containing 12 & Q8WUD4 & CCDC12 \\
\hline Conserved oligomeric Golgi complex subunit 1 & Q8WTW3 & COG1 \\
\hline DNA topoisomerase 1 & P11387 & TOP1 \\
\hline Dolichyl-diphosphooligosaccharide-protein glycosyltransferase subunit STT3B & Q8TCJ2 & STT3B \\
\hline Dynamin-like $120 \mathrm{kDa}$ protein, mitochondrial & $\mathrm{O} 60313$ & OPA1 \\
\hline EH domain-containing protein 4 & Q9H223 & EHD4 \\
\hline Elongation factor 1-alpha 2 & Q05639 & EEF1A2 \\
\hline Epiplakin & P58107 & EPPK1 \\
\hline Eukaryotic initiation factor $4 \mathrm{~A}-\mathrm{III}$ & P38919 & EIF4A3 \\
\hline Eukaryotic translation initiation factor 4 gamma 1 & Q04637 & EIF4G1 \\
\hline Eukaryotic translation initiation factor 4 gamma 3 & O43432 & EIF4G3 \\
\hline Formin-binding protein 1-like & Q5T0N5 & FNBP1L \\
\hline Haloacid dehalogenase like hydrolase domain containing 3 & Q9BSH5 & HDHD3 \\
\hline Haloacid dehalogenase-like hydrolase domain-containing 5 & Q9BXW7 & CECR5 \\
\hline Heat shock protein $105 \mathrm{kDa}$ and $70 \mathrm{kDa}$ proteins & Q92598 & HSPH1 \\
\hline Heat shock protein family A member 4 & P34932 & HSPA4 \\
\hline Heme-binding protein 2 & Q9Y5Z4 & HEBP2 \\
\hline Hepatoma-derived growth factor-related protein 3 & Q9Y3E1 & HDGFRP3 \\
\hline High mobility group protein B1 & P09429 & HMGB1 \\
\hline Hydroxymethylglutaryl-CoA synthase, cytoplasmic & Q01581 & HMGCS1 \\
\hline Isocitrate dehydrogenase [NAD] subunit alpha, mitochondrial & P50213 & $I D H 3 A$ \\
\hline Isocitrate dehydrogenase [NADP], mitochondrial & P48735 & $\mathrm{IDH} 2$ \\
\hline Magnesium transporter protein 1 & Q9H0U3 & MAGT1 \\
\hline Mediator of RNA polymerase II transcription subunit 14 & O60244 & MED14 \\
\hline
\end{tabular}


Table 3. Cont.

\begin{tabular}{|c|c|c|}
\hline Protein Name & UniProt $^{1}$ & Gene $^{2}$ \\
\hline Mitotic interactor and substrate of PLK1 & Q8IVT2 & MISP \\
\hline Myosin regulatory light chain $12 \mathrm{~A}$ & P19105 & MYL12A \\
\hline NADH-ubiquinone oxidoreductase $75 \mathrm{kDa}$ subunit, mitochondrial & P28331 & NDUFS1 \\
\hline Nitric oxide synthase-interacting protein & Q9Y314 & NOSIP \\
\hline Non-POU domain-containing octamer-binding protein & Q15233 & NONO \\
\hline Nucleoside diphosphate-linked moiety X motif 19 & A8MXV4 & NUDT19 \\
\hline Paraspeckle component 1 & Q8WXF1 & PSPC1 \\
\hline PHD finger protein 14 & O94880 & PHF14 \\
\hline Pogo transposable element with ZNF domain & Q7Z3K3 & POGZ \\
\hline Probable ATP-dependent RNA helicase DDX6 & P26196 & $D D X 6$ \\
\hline Prolyl endopeptidase & P48147 & PREP \\
\hline Protein S100-A13 & Q99584 & S100A13 \\
\hline Putative oxidoreductase GLYR1 & Q49A26 & GLYR1 \\
\hline Ras-related GTP-binding protein A & Q7L523 & RRAGA \\
\hline Small nuclear ribonucleoprotein $\mathrm{E}$ & P62304 & SNRPE \\
\hline SWI/SNF complex subunit SMARCC1 & Q92922 & SMARCC1 \\
\hline SWI/SNF complex subunit SMARCC2 & Q8TAQ2 & SMARCC2 \\
\hline SWI/SNF-related matrix-associated actin-dependent regulator of chromatin subfamily A member 5 & O60264 & SMARCA5 \\
\hline T-complex protein 1 subunit beta; & P78371 & CCT2 \\
\hline T-complex protein 1 subunit epsilon & P48643 & CCT5 \\
\hline Transcription initiation factor TFIID subunit 4 & O00268 & TAF4 \\
\hline Transcriptional repressor p66-alpha & Q86YP4 & GATAD2A \\
\hline Transcriptional repressor p66-beta & Q8WXI9 & GATAD2B \\
\hline Transducin beta-like protein 3; & Q12788 & $T B L 3$ \\
\hline Tyrosine-protein phosphatase non-receptor type 11 & Q06124 & PTPN11 \\
\hline UBX domain-containing protein 7 & O94888 & UBXN7 \\
\hline
\end{tabular}

${ }^{1}$ UniProt accession number. ${ }^{2}$ Entrez gene ID.

Among these proteins, DNA topoisomerase 1 (TOP1) which is involved in the DNA replication pathway, stands out. Figure 5 shows the large number of interactions between these 61 proteins. Interactions between several members of the SWI/SNF family (SWI/SNF complex subunit SMARCC1 (SMARCC1), SWI/SNF complex subunit SMARCC2 (SMARCC2), and SWI/SNF-related matrix-associated actin-dependent regulator of chromatin A5 (SMARCA5)) are noteworthy, along with resistance to these HSP90 inhibitors being related to the WNT signaling pathway. On the other hand, we also found 110 and 1711 proteins specifically expressed in cell lines exhibiting the most resistance to 17-AAG and IPI-504, respectively (Table S4).

With respect to proteins specifically expressed in response to STA-9090 and AUY922 treatment, we identified 20 and 1256 proteins, respectively. Decaprenyl diphosphate synthase subunit 2 (PDSS2) was the only protein associated with resistance that was common to both inhibitors (Figure 4B and Table S4). 


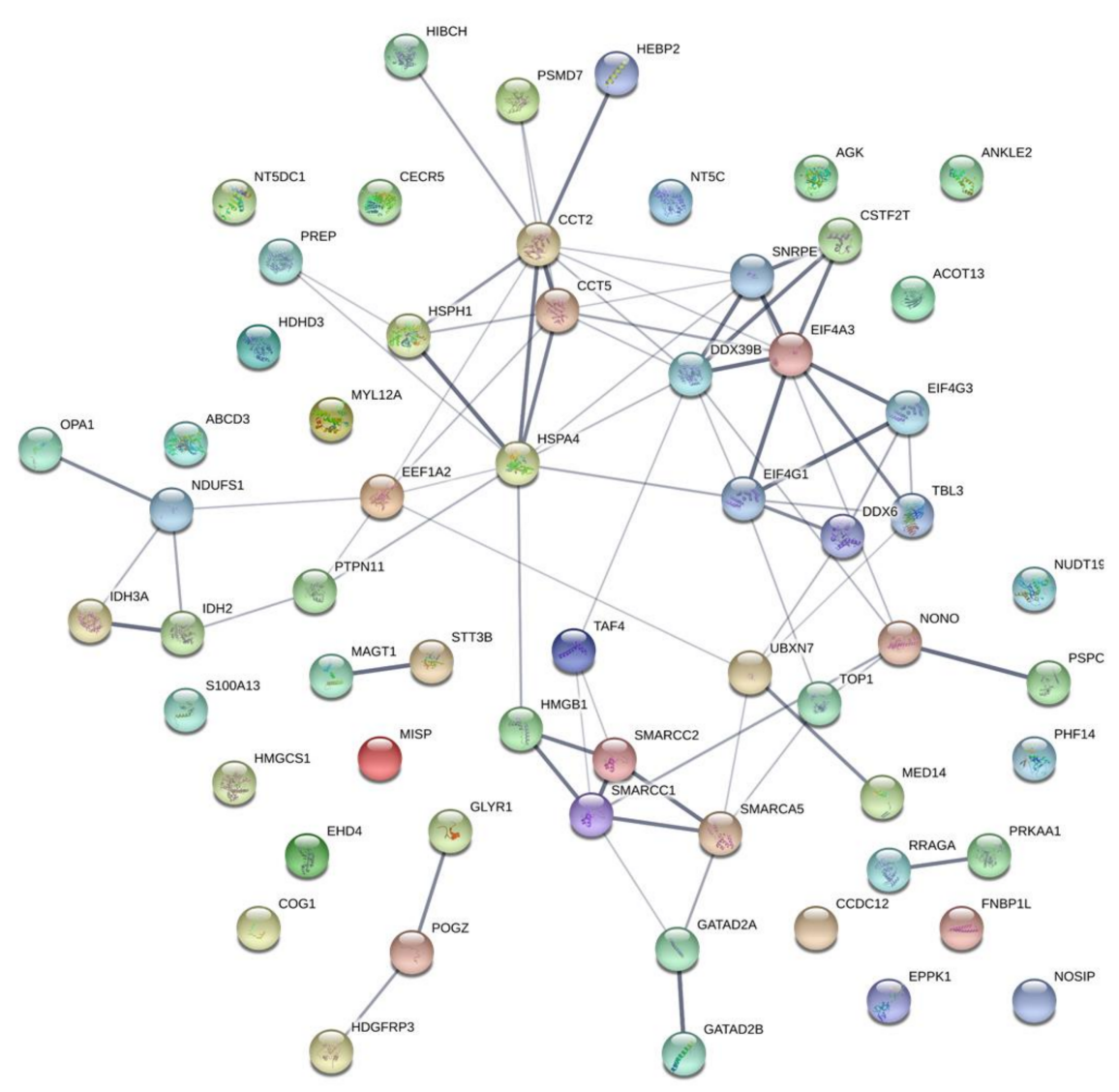

Figure 5. Map of interactions of common proteins related to geldanamycin resistance.

\subsection{Candidate Pathways Associated with Susceptibility to HSP90 Inhibition}

The PANTHER database was used to perform functional analyses of proteins significantly correlated with responses to HSP90 inhibitors. For a total of 58 biological pathways that were identified, only 6 (arginine biosynthesis, endogenous cannabinoid signaling, GABA-B receptor II signaling, gonadotropin-releasing hormone receptor pathway, opioid proenkephalin pathway, and opioid proopiomelanocortin pathway) were exclusively associated with sensitivity to the studied inhibitors. Interestingly, a greater number of pathways were related to resistance to HSP90 inhibition (Table 4).

Table 4. Pathways related to responses to HSP90 inhibitors.

\begin{tabular}{|c|c|}
\hline Sensitivity & Resistance \\
\hline Arginine biosynthesis & Adrenaline and noradrenaline biosynthesis \\
\hline Endogenous cannabinoid signaling & $\begin{array}{c}\text { Alzheimer's disease-amyloid secretase } \\
\text { pathway }\end{array}$ \\
\hline \multirow{8}{*}{$\begin{array}{c}\text { GABA-B receptor II signaling } \\
\text { Gonadotropin-releasing hormone receptor } \\
\text { pathway } \\
\text { Opioid proenkephalin pathway } \\
\text { Opioid proopiomelanocortin pathway }\end{array}$} & Blood coagulation \\
\hline & Coenzyme A biosynthesis \\
\hline & General transcription regulation \\
\hline & Ornithine degradation \\
\hline & p53 pathway by glucose deprivation \\
\hline & Purine metabolism \\
\hline & Toll receptor signaling pathway \\
\hline & Vasopressin synthesis \\
\hline
\end{tabular}

Among them, the Toll receptor signaling pathway and the p53 pathway by glucose deprivation are relevant given their importance in tumor growth. Proteins involved in the p53 pathway by glucose deprivation identified in our work were immunoglobulin binding 
protein 1 (IGBP1), AKT serine/threonine kinase 1 (AKT1), AKT serine/threonine kinase 2 (AKT2), protein kinase AMP-activated catalytic subunit alpha 1 (PRKAA1), mechanistic target of rapamycin kinase (mTOR), ribosomal protein S6 kinase beta-1 (S6K), eukaryotic translation initiation factor 4E-binding protein 1 (4E-BP1), GTP-binding protein Rheb (Rheb), and tuberin (TSC2). Most proteins showed higher basal abundance in HSP90inhibitor-resistant cell lines than in drug-sensitive ones, with the exception of STA-9090 (Figure 6).

A

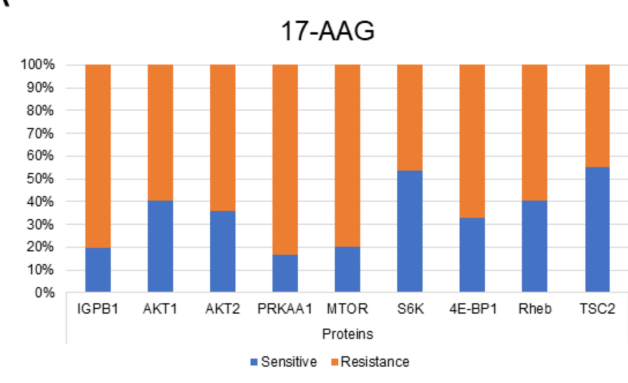

C

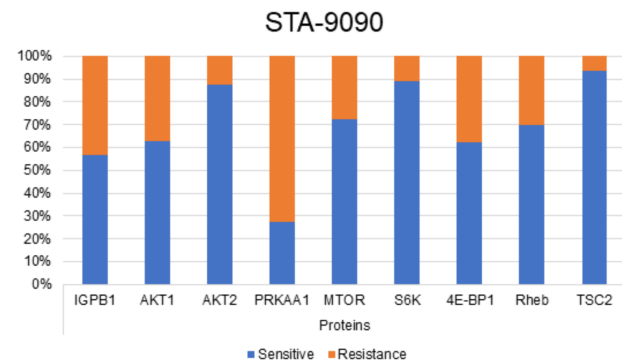

B

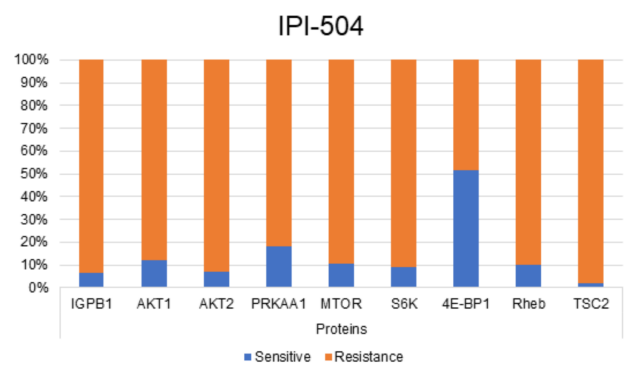

D

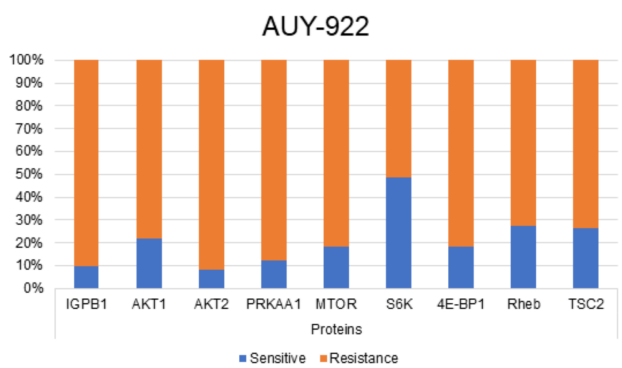

Figure 6. Basal abundance of proteins involved in the p53 pathway by glucose deprivation in cell lines sensitive or resistant to geldanamycin derivatives (17-AAG (A) and IPI-504 (B)) and radicicol derivatives (STA-9090 (C) and AUY-922 (D)).

\section{Discussion}

In this study, we used iTRAQ and mass spectrometry technology to identify proteins that served as predictive biomarkers describing sensitivity or resistance to HSP90 inhibition in lung adenocarcinoma cell lines. To this end, we analyzed the differential expression of specific proteins prior to and after inhibitor treatment and correlated our findings to the roles these proteins may play in signaling pathways involving tumorigenesis. Such an approach should enable us to optimize the manner in which HPS90 is used as a therapeutic target in lung cancer.

Treatment with the radicicol derivatives STA-9090 and AUY-922 revealed a large number of proteins significantly correlated with tumor cell sensitivity; this number was considerably greater than the number of proteins associated with resistance to these drugs. In contrast, more proteins related to resistance to the geldanamycin derivatives 17-AAG and IPI-504 were detected than those related to sensitivity. These data potentially indicate a greater efficacy of HSP90 inhibition through radicicol derivatives in lung adenocarcinoma cell lines and may explain why better clinical results have been achieved in lung cancer patients after treatment with radicicol derivatives [37], the only inhibitor family associated with ongoing clinical trials (NCT02503709 and NCT02535338).

Given differences in clinical results obtained according to the HSP90 inhibitor family used, this study focused on identifying biomarkers associated with the efficacy of geldanamycin and radicicol derivatives. As shown in our results, 12 proteins (AK2, ATP5D, DLGAP5, GPAA1, GNAI3, LDHB, MRPS23, PTBP1/3, PDHX, UFM1, and ZFAND1) were correlated with sensitivity to the geldanamycin analogs 17-AAG and IPI-504. Of these 
proteins, an association between $\mathrm{LDHB}$ and the antitumoral response has been proposed. Moreover, among the different isoenzymes of LDH, two of them-LDHB and LDHA-were reported as deregulated proteins in cancer cells and are involved in the regulation of tumorstroma nutrient exchange [38]. A relationship between LDHB expression and response to other antitumor therapies, specifically adjuvant chemotherapy in patients with breast cancer, was also previously described [39]. Regarding NSCLC, it is noteworthy that the GALAXY-1 clinical trial showed that patients with high LDH expression responded better to a combination therapy consisting of the HSP90 inhibitor STA-9090 and docetaxel [29]. These data, despite not distinguishing between the A and B isoforms of $\mathrm{LDH}$, together with the demonstrated importance of LDHB for the growth of certain lung adenocarcinomas [40], support the potential of LDHB as a predictive biomarker of the efficacy of geldanamycin derivatives. On the other hand, with respect to proteins related to resistance to the geldanamycin analogs 17-AAG and IPI-504, the presence of TOP1 among the 61 proteins identified was of note. In different tumor types, including lung cancer, a high expression of this important enzyme involved in DNA replication and transcription has been detected when compared to healthy tissue [41]. Furthermore, a low level of TOP1 expression has been proposed as a good prognostic factor related to greater overall survival in postoperative NSCLC patients [42]. These observations are consistent with results obtained in our work, where the TOP1 expression level and the DNA replication pathway in which it is involved are positively correlated with resistance to geldanamycin analogs. Based on this, and since different TOP1 inhibitors are used clinically for the treatment of small-cell lung, ovarian, and cervical cancer [43], their use in combination with 17-AAG or IPI-504 could be an interesting therapeutic strategy to be tested in lung adenocarcinoma patients presenting with high TOP1 expression. Our results also showed that Wnt signaling could be involved in the lack of response to 17-AAG and IPI-504 due to correlations between basal abundances of SMARCC1, SMARCC2, and SMARCA5 and resistance to geldanamycin derivatives. This pathway is involved in NSCLC initiation, progression, and metastasis [44,45]. Therefore, it is not surprising that a higher expression of SMARCC2 has been reported in tissue from NSCLC patients when compared to normal tissue [46]. Furthermore, in line with our data, SMARCC1 was previously described as a potential biomarker of efficacy with cytotoxic chemotherapy [47]. In addition, in bladder cancer, $\mathrm{Li}$ et al. observed decreased SMARCC1 expression levels after HSP90 inhibition, supporting our results [48]. Finally, it is worth highlighting that SMARCA5, which is overexpressed in different tumor types $[49,50]$, forms a chromatin-remodeling complex with bromodomain adjacent to zinc finger domain 1B (BAZ1B) that facilitates the access of TOP1 at the replication fork. The overexpression of BAZ1B, and therefore that of SMARCA5, could potentiate the function of TOP1 during DNA replication, affecting the response of cancer cells to TOP1 inhibitors and to other treatments affecting replication [51]. These data might connect the two pathways proposed in this study, relating resistance to 17-AAG and IPI-504 with DNA replication and Wnt signaling. Taken together, further research is required on SMARCC1, SMARCC2, and SMARCA5, together with TOP1, as predictive biomarkers of resistance to geldanamycin derivatives as HSP90 inhibitors in lung adenocarcinoma.

Regarding radicicol derivatives, the relationship between the basal abundance of RTKN and its sensitivity to this family of HSP90 inhibitors is relevant. Among other functions, this Rho GTPase effector [52] is a key regulator of the cytoskeleton in multiple cellular functions, such as migration, adhesion, and cytokinesis [53]. Notably, our work identified cytoskeletal regulation by the Rho GTPases pathway as the only pathway associated with sensitivity to radicicol analogs in the studied lung adenocarcinoma cell lines. To this end, the radicicol derivative AUY-922 was shown to exert a strong antimigratory effect on tumor cells due primarily to reorganization of the cytoskeleton [54]. We, therefore, suggest that cytoskeletal properties and related HSP90 client proteins could be involved in favorable responses to the inhibition of this chaperone. On the other hand, among the proteins related to resistance to STA-9090 and AUY-922 treatments, a subunit of the enzyme decaprenyl diphosphate synthase, decaprenyl diphosphate synthase subunit 2 (PDSS2), plays a critical 
role in coenzyme Q10 (CoQ10) biosynthesis [55]. Low PDSS2 expression has been reported in different tumor types, including NSCLC, where the role of this protein as a tumor suppressor has been described [56,57]. However, research has demonstrated an association between CoQ10 and the decrease in the effectiveness of different chemotherapeutic agents in cancer cells due to the antioxidant activity of this coenzyme [58]. These observations support our results, where the basal abundance of PDSS2, and therefore CoQ10, was significantly correlated with resistance to radicicol derivatives in lung adenocarcinoma cell lines.

It is important to highlight that several proteins included in the identified protein pattern are involved in the HSP90 interactome [59]. There are unimpeachable pieces of evidence showing that the degradation of these client proteins is fundamental in the response to HSP90 inhibitors [8,24]; however, there is no information about their predictive role. Furthermore, the broad protein network of HSP90 includes not only its clients but also many proteins that, unlike clients, are overexpressed after its inhibition [48]. Nonetheless, due to the crucial role of the HSP90 interactome in the response to its inhibition, it is essential to know which proteins in our profile are clients of this chaperone [1]. Specifically, we found that ATP5D, TUBB2A, TUBB6, 26 S proteasome non-ATPase regulatory subunit (7PSMD7), PRKAA1, conserved oligomeric Golgi complex subunit 1 (COG1), and myosin regulatory light chain 12A (MYL12A) are HSP90 client proteins with a potential predictive role of resistance or sensitivity to HSP90 inhibitors. Therefore, changes in these proteins, which are involved in the cytoskeleton, proteasome, ATP synthesis, or p53 pathway by glucose deprivation, among others, could be directly or indirectly affecting the response to the blockade of HSP90. Therefore, it would be essential to study these interesting proteins in depth to know how their basal abundances may be related, in addition to sensitivity or resistance to HSP90 inhibitors, with the response to them.

We also carried out a functional annotation of all proteins whose basal abundance was related to sensitivity or resistance to HSP90 inhibitors. Among all of the pathways correlated with sensitivity to HSP90 inhibition, the role of the arginine biosynthesis pathway is highly relevant, with this amino acid highly implicated in cell proliferation, as previously described [60]. Based on this premise, the potential role of argininosuccinate synthase 1 (ASS1) [61], a key enzyme in arginine biosynthesis and which we identified as a predictor of sensitivity to HSP90 inhibitors in lung adenocarcinoma, warrants attention. Moreover, among the pathways related to resistance to HSP90 inhibitors, we identified the relevance of p53 by glucose deprivation. Our analyses detected a higher basal abundance of nine proteins (IGPB1, AKT1, AKT2, PRKAA1, mTOR, S6K, 4E-BP1, Rheb, and TSC2) involved in the 53 pathway by glucose deprivation in resistant cell lines compared to those sensitive to HSP90 inhibitors. These results found for the majority of inhibitors studied, especially for AUY-922, were significant and in line with those of recent researchers who described this pathway as involved in the induction of cell death by altering multidrug resistance [62-64]. However, STA-9090 was the only inhibitor whose lack of response suggests that it must be related to the alteration of another pathway. Therefore, it is important to extend our knowledge and understanding of the proteins involved in this p53 by glucose deprivation pathway given their possible predictive role of response to HPS90 inhibition in lung adenocarcinoma.

Given that our results are based exclusively on in vitro data, the in vivo validation of potential biomarkers and proposed pathways related to the efficacy of HSP90 inhibition in lung adenocarcinoma will be the next important step to translate these findings into clinical practice. However, a limitation to this is the lack of patients undergoing treatment with HSP90 inhibitors, mainly due to the toxicity presented by clinically tested inhibitors and the lack of treatment response in patients with lung adenocarcinoma. The use of the proteins presented in this study as potential predictive biomarkers of response to inhibitors highlights important issues regarding the correct selection of lung adenocarcinoma patients, which would increase the potential benefits of HSP90 inhibition as a therapeutic strategy. 


\section{Materials and Methods \\ 4.1. Cell Culture}

Human lung adenocarcinoma cell lines (HCC827, H1975, H1650, H2009, H358, H2228, Calu-3, H1437, and H1781) were obtained from the American Type Culture Collection (ATCC). Dr. Sánchez and Dr. Koivunen kindly provided the A549 and H3122 cell lines, respectively. Cells were cultured in RPMI-1640 medium (Sigma-Aldrich, Saint Louis, MO, USA), with the exception of A549 and Calu-3 cells, which were propagated in DMEM (Sigma-Aldrich). All cell lines were supplemented with 10\% fetal bovine serum (FBS, TICO Europe, Amstelveen, The Netherlands), $1 \%$ antibiotic-antimycotic solution (SigmaAldrich), and $1 \%$ glutamine. Cells were maintained at $37^{\circ} \mathrm{C}$ in a humidified incubator under a $5 \% \mathrm{CO}_{2}$ and $95 \%$ air atmosphere and subcultured every 2-3 days. Cells were authenticated and regularly checked for mycoplasma.

\subsection{Cell Viability}

Cells in the log phase were plated at $3 \times 10^{3} /$ well in 96-well plates for $24 \mathrm{~h}$. HSP90 inhibitor derivatives of geldanamycin (tanespimycin (17-AAG) (Selleckchem, Munich, Germany) and retaspimycin hydrochloride (IPI-504) (Eurodiagnóstico, Madrid, Spain)) and radicicol derivatives (ganetespib (STA-9090) and luminespib (AUY-922) (Selleckchem, Munich, Germany)) were dissolved in dimethyl sulfoxide (DMSO) as stock solutions according to the manufacturers' instructions. Cells were then independently treated with HSP90 inhibitors at concentrations ranging from $0.33 \mathrm{nM}$ to $20 \mu \mathrm{M}$ for $96 \mathrm{~h}$. The halfmaximal inhibitory concentration $\left(\mathrm{IC}_{50}\right)$ for each inhibitor was determined from the doseresponse curve. Three independent experiments were performed at each concentration.

\subsection{Proteomic Sample Preparation}

Each of the cell lines was grown in $10 \mathrm{~cm}$ diameter dishes for $24 \mathrm{~h}$. Then, cells were collected, precipitated, and washed with ice-cold PBS. Next, the cells were resuspended in lysis buffer containing $1 \mathrm{M}$ TEAB (triethylammonium bicarbonate, Sigma-Aldrich), $0.05 \%$ SDS, 1:100 phosphatase inhibitor cocktail (PhosSTOP EASYpack, Roche, Basel, Switzerland), 1:100 protease inhibitor cocktail (cOmplete Mini EDTA-free, Roche), and $0.002 \%$ benzonase (Novagen, Buenos Aires, Argentina) and lysed for $1 \mathrm{~h}$ on ice with intermittent vortexing. Cell debris was removed by centrifugation at $14,000 \mathrm{rpm}$ for $15 \mathrm{~min}$ at $4{ }^{\circ} \mathrm{C}$. Supernatants were collected, and protein concentrations assayed using Qubit fluorometric quantitation (Life Technologies, Carlsbad, CA, USA). Finally, $100 \mu \mathrm{g}$ of each sample was aliquoted and stored at $-80{ }^{\circ} \mathrm{C}$ until required. These lysates were prepared from each cell line and condition.

\subsection{Trypsin Digestion and iTRAQ Labeling}

The proteins from each sample were reduced with $50 \mathrm{mM}$ TCEP (tris-(2-carboxyethyl) phosphine, $\mathrm{AB}$ Sciex) at $60^{\circ} \mathrm{C}$ for $1 \mathrm{~h}$ with shaking and were subsequently alkylated with $200 \mathrm{mM}$ MMTS (S-methyl methanethiosulfonate, AB Sciex) for $10 \mathrm{~min}$ at room temperature. Proteins were then trypsinized at $37^{\circ} \mathrm{C}$ in a $10: 1$ ratio $(w / w)$ of substrate/enzyme (Promega) in a water bath overnight. Finally, a speed-vac concentrator was used for drying the peptides.

The iTRAQ-labeling assay was conducted according to the manufacturer's instructions (iTRAQ 8-plex, AB Sciex). Briefly, each tryptic digest was reconstituted in $1 \mathrm{M}$ TEAB and labeled with one isobaric amine-reactive tag, with 113 being the focus in the present work. After $2 \mathrm{~h}$ of incubation, labeled samples were pooled, dried at $45^{\circ} \mathrm{C}$, and stored overnight at $4{ }^{\circ} \mathrm{C}$.

\subsection{Cleaning and Fractionation}

iTRAQ-labeled samples were desalted using Oasis HLB C18 cartridges (Waters, Milford, MA, USA) and dried using a vacuum centrifuge. Peptides were then prefractionated using MCX Oasis columns (Waters) and increasing concentrations (50, 100, 200, 300, 400, 
$500,600,700,800$, and $900 \mathrm{mM}$ and 1, 1.5, and $2 \mathrm{M}$ ) of ammonium formate. A total of 13 fractions were collected and individually washed using C18 cartridges, after which they were dried.

\subsection{NanoLC-MS/MS Analysis}

Peptides from each fraction were separated using nano-liquid chromatography (nano LC 1000, Thermo Scientific) and analyzed by means of nano-electrospray ionization (Proxeon Biosystems, Odense, Denmark) connected to a Q Exactive Plus Orbitrap mass spectrometer (Thermo Scientific). Briefly, $13 \mu \mathrm{L}$ of each fraction was loaded, preconcentrated, and washed in an Acclaim PepMap $(75 \mu \mathrm{m} \times 2 \mathrm{~cm}$, nanoViper, C18, $3 \mu \mathrm{m}, 100 \AA)$ precolumn (Thermo Scientific). Peptides were separated in an analytical column $(75 \mu \mathrm{m} \times 15 \mathrm{~cm}$, nanoViper, C18, $2 \mu \mathrm{m}, 100 \AA$ (Acclaim PepMap RSLC)) (Thermo Scientific) for $240 \mathrm{~min}$ at $200 \mathrm{~nL} / \mathrm{min}$.

Peptides were eluted with a gradient of buffer A $\left(0.1 \%\right.$ formic acid, $\left.100 \% \mathrm{H}_{2} \mathrm{O}\right)$ to buffer B (0.1\% formic acid, 100\% acetonitrile) as follows: 0-220 min, 0-35\% buffer B; 220$230 \mathrm{~min}, 35-45 \%$ buffer B; and 230-240 min, 45-95\% buffer B. The Q Exactive system was used for MS/MS analysis in the positive ion and information-dependent acquisition modes. Mass spectra were acquired over a scan range of 200 to $1800 \mathrm{~m} / \mathrm{z}$ with a resolution of 70,000 FWHM from $m / z$ 100. Up to 15 precursors with a charge state $\geq 2$ were selected and incorporated into an exclusion list for $60 \mathrm{~s}$. Peptide identification and quantification were carried out considering the higher-energy collisional dissociation (HCD) spectrum. HCD fragmentation was performed with a collision energy of $32 \%$ to maximize the abundance of iTRAQ reporter ions.

\subsection{Protein Identification and Quantification}

Peptide identification and quantification were conducted using the Sequest HT search engine and Percolator, both of which were included in Proteome Discoverer 1.4 software (Thermo Fisher Scientific). Each MS/MS spectrum was searched against the UniProt Database for Homo sapiens. The parameter considered for the search was digestion enzyme (trypsin); iTRAQ 8-plex peptide label (N-terminal) and iTRAQ 8-plex peptide label (lysine) were used as fixed modifications, and the oxidation of methionine and carbamidomethylation of cysteine were selected as variable modifications. Subsequently, the relative peptide abundances were determined using the MS/MS scans of iTRAQ-labeled peptides, where the ratios of peak areas of the $i T R A Q$ reporter ions reflect the relative abundances of the peptides and therefore of proteins in the samples. Proteins had to contain at least two unique peptides with a significance score $\geq 95 \%$, a ratio with a $p$-value $\leq 0.05$, and a false discovery rate $(\mathrm{FDR})<2$ to be considered quantifiable.

\subsection{Data Analysis}

To identify potential predictive proteins related to sensitivity or resistance to HSP90 inhibitors, we analyzed the proteomic signature in human lung adenocarcinoma cells prior to treatment and correlated this with the efficacy of the response to treatment. The sum of the intensities of the peptides identified in the control group labeled with 113 was employed to calculate the basal abundances of proteins in the pretreated cell lines. On the other hand, those proteins commonly identified in the three cell lines most sensitive or resistant to each HSP90 inhibitor were selected. Then, for each of these proteins of interest, the Spearman coefficient was employed to test for a potential correlation between the basal abundance and the $\mathrm{IC}_{50}$ value of each inhibitor in all of the cell lines where these proteins were identified. Only proteins with a significant correlation $(p$-value $<0.05)$ were used in the subsequent analysis.

Sensitivity- or resistance-related proteins found in common for each HSP90 inhibitor family were grouped in Venn-Euler diagrams using the jvenn (http:/ jvenn.toulouse. inra.fr/app/index.html) program. Next, proteins of interest were functionally analyzed and categorized according to their biological processes and molecular functions using the 
PANTHER (Protein ANalysis THrough Evolutionary Relationships) online database (http: / / pantherdb.org/ accessed on May 2020). Finally, known and predicted protein-protein interaction networks of proteins were built based on the publicly available Search Tool for the Retrieval of Interacting Genes/Proteins (STRING) database (https:/ /string-db.org/ accessed on May 2020). Only results with a Benjamini-Hochberg adjusted $p$-value of less than 0.05 were considered statistically significant.

\title{
5. Conclusions
}

We analyzed proteins whose basal abundances were correlated with response to HSP90 inhibitors in a panel of lung adenocarcinoma cell lines using iTRAQ-based assays. A total of 3219 proteins were associated with sensitivity to treatment with HSP90 inhibitors, and 3384 proteins were associated with resistance to treatment with HSP90 inhibitors. It is relevant to highlight that among all the proteins identified in our predictive profile, seven of them are HSP90 client proteins, which could be indicating an ensured effect of inhibition. In addition, we found specific differences according to the two families of inhibitors used; this was highlighted by the roles of LDHB and TOP1 proteins in sensitivity and resistance to geldanamycin analogs, respectively. In the case of radicicol derivatives, RTKN was correlated with sensitivity to these treatments, and PDSS2 was correlated with resistance to these treatments. In addition, functional annotation analyses of identified proteins revealed that the p53 pathway by glucose deprivation and arginine biosynthesis were correlated with resistance and sensitivity to HSP90 inhibitors, respectively. A thorough in vivo validation of our findings is required for future clinical use of these inhibitors to treat human lung adenocarcinoma.

Supplementary Materials: Supplementary materials can be found at https://www.mdpi.com/1422 $-0067 / 22 / 5 / 2538 / s 1$. Table S1. Proteins identified in human cell lines from lung adenocarcinoma with the highest sensitivity to each geldanamycin derivative, Table S2. Protein profile associated with sensitivity to both geldanamycin derivatives in lung adenocarcinoma, Table S3. Proteins related to sensitivity to radicicol analogs in lung adenocarcinoma, Table S4. Proteins specifically expressed in lung adenocarcinoma cell lines with the highest resistance to 17-AAG and IPI-504.

Author Contributions: Conceptualization Á.M., S.M.-P., and L.P.-A.; methodology, Á.M., M.D.P., D.G.-S., I.F., S.M.-P., L.O., and Á.Q.-V.; investigation, Á.M., L.P.-A., and S.M.-P.; formal analysis, Á.M., D.G.-S., and S.M.-P.; writing—original draft preparation, Á.M., S.M.-P., and L.P.-A.; writing—review and editing, Á.M., I.F., D.G.-S., M.D.P., L.O., Á.Q.-V., S.M.-P., and L.P.-A.; supervision, S.M.-P. and L.P.-A.; funding acquisition L.P.-A. All authors have read and agreed to the published version of the manuscript.

Funding: L.P.A. was funded by the Comunidad de Madrid, CAM, (B2017/BMD3884), ISCIII (PIE15/00076, PI17/00778 and DTS17/00089), and CIBERONC (CB16/12/00442), and co-funded by FEDER from Regional Development European Funds (European Union). S.M.P. was funded by the Fundación Mutua Madrileña (2014), Ministry of Health and Social Welfare of the Junta de Andalucía (Nicolas Monardes Program RC-0004-2020 and OH-0022-2018), ISCIII (PI17/00033 and PI20/01109), and co-funded by European Regional Development Fund "A way to make Europe" I.F. was funded by the AECC (AIO2015) and ISCIII (PI16/01311) and co-funded by FEDER from Regional Development European Funds (European Union).

Institutional Review Board Statement: Not applicable.

Informed Consent Statement: Not applicable.

Data Availability Statement: Not applicable.

Conflicts of Interest: The authors declare no conflict of interest.

\author{
Abbreviations \\ 17-AAG Tanespimycin \\ 7PSMD7 26S proteasome non-ATPase regulatory subunit
}




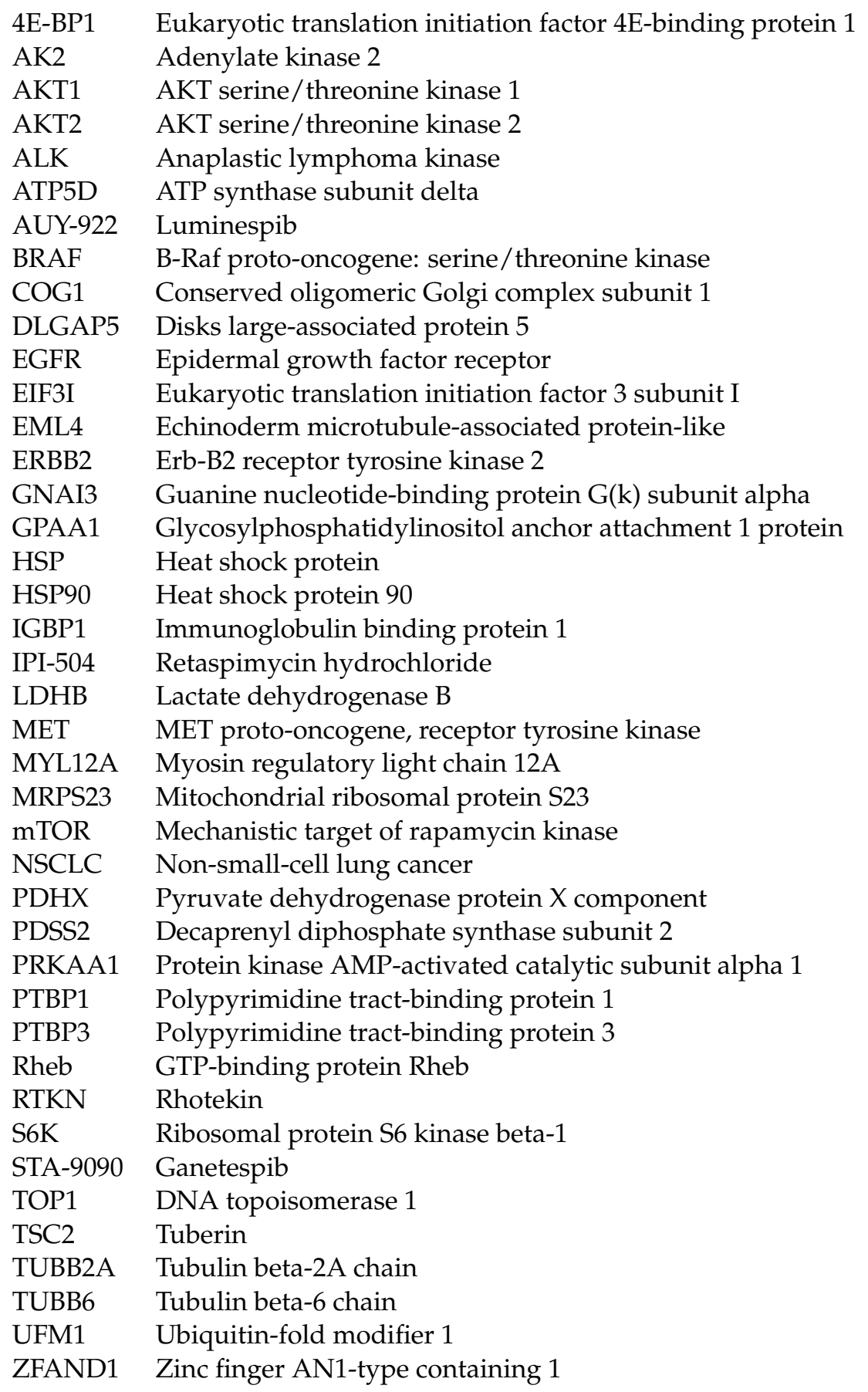

\section{References}

1. Hoter, A.; EI-Sabban, M.E.; Naim, H.Y. The HSP90 Family: Structure, Regulation, Function, and Implications in Health and Disease. Int. J. Mol. Sci. 2018, 19, 2560. [CrossRef] [PubMed]

2. Echeverria, P.C.; Bernthaler, A.; Dupuis, P.; Mayer, B.; Picard, D. An interaction network predicted from public data as a discovery tool: Application to the Hsp90 molecular chaperone machine. PLoS ONE 2011, 6, e26044. [CrossRef]

3. Tatokoro, M.; Koga, F.; Yoshida, S.; Kihara, K. Heat shock protein 90 targeting therapy: State of the art and future perspective. Excli J. 2015, 14, 48-58.

4. Hanahan, D.; Weinberg, R.A. Hallmarks of cancer: The next generation. Cell 2011, 144, 646-674. [CrossRef]

5. Whitesell, L.; Lindquist, S.L. HSP90 and the chaperoning of cancer. Nat. Rev. Cancer 2005, 5, 761-772. [CrossRef]

6. Butler, L.M.; Ferraldeschi, R.; Armstrong, H.K.; Centenera, M.M.; Workman, P. Maximizing the Therapeutic Potential of HSP90 Inhibitors. Mol. Cancer Res. 2015, 13, 1445-1451. [CrossRef] [PubMed]

7. Workman, P.; Burrows, F.; Neckers, L.; Rosen, N. Drugging the cancer chaperone HSP90: Combinatorial therapeutic exploitation of oncogene addiction and tumor stress. Ann. N. Y. Acad. Sci. 2007, 1113, 202-216. [CrossRef] [PubMed] 
8. Neckers, L.; Workman, P. Hsp90 molecular chaperone inhibitors: Are we there yet? Clin. Cancer Res. 2012, 18, 64-76. [CrossRef] [PubMed]

9. Bray, F.; Ferlay, J.; Soerjomataram, I.; Siegel, R.L.; Torre, L.A.; Jemal, A. Global cancer statistics 2018: GLOBOCAN estimates of incidence and mortality worldwide for 36 cancers in 185 countries. CA Cancer J. Clin. 2018, 68, 394-424. [CrossRef]

10. Shimamura, T.; Lowell, A.M.; Engelman, J.A.; Shapiro, G.I. Epidermal growth factor receptors harboring kinase domain mutations associate with the heat shock protein 90 chaperone and are destabilized following exposure to geldanamycins. Cancer Res. 2005, 65, 6401-6408. [CrossRef] [PubMed]

11. Xu, W.; Soga, S.; Beebe, K.; Lee, M.J.; Kim, Y.S.; Trepel, J.; Neckers, L. Sensitivity of epidermal growth factor receptor and ErbB2 exon 20 insertion mutants to Hsp90 inhibition. Br. J. Cancer 2007, 97, 741-744. [CrossRef]

12. Wang, S.; Pashtan, I.; Tsutsumi, S.; Xu, W.; Neckers, L. Cancer cells harboring MET gene amplification activate alternative signaling pathways to escape MET inhibition but remain sensitive to Hsp90 inhibitors. Cell Cycle 2009, 8, 2050-2056. [CrossRef] [PubMed]

13. Da Rocha Dias, S.; Friedlos, F.; Light, Y.; Springer, C.; Workman, P.; Marais, R. Activated B-RAF is an Hsp90 client protein that is targeted by the anticancer drug 17-allylamino-17-demethoxygeldanamycin. Cancer Res. 2005, 65, 10686-10691. [CrossRef] [PubMed]

14. Normant, E.; Paez, G.; West, K.A.; Lim, A.R.; Slocum, K.L.; Tunkey, C.; McDougall, J.; Wylie, A.A.; Robison, K.; Caliri, K.; et al. The Hsp90 inhibitor IPI-504 rapidly lowers EML4-ALK levels and induces tumor regression in ALK-driven NSCLC models. Oncogene 2011, 30, 2581-2586. [CrossRef]

15. Esfahani, K.; Cohen, V. HSP90 as a novel molecular target in non-small-cell lung cancer. Lung Cancer (Auckl.) 2016, 7, 11-17. [PubMed]

16. Gallegos Ruiz, M.I.; Floor, K.; Roepman, P.; Rodriguez, J.A.; Meijer, G.A.; Mooi, W.J.; Jassem, E.; Niklinski, J.; Muley, T.; van Zandwijk, N.; et al. Integration of gene dosage and gene expression in non-small cell lung cancer, identification of HSP90 as potential target. PLoS ONE 2008, 3, e0001722. [CrossRef] [PubMed]

17. Hendriks, L.E.L.; Dingemans, A.C. Heat shock protein antagonists in early stage clinical trials for NSCLC. Expert. Opin. Investig. Drugs 2017, 26, 541-550. [CrossRef]

18. Proia, D.A.; Sang, J.; He, S.; Smith, D.L.; Sequeira, M.; Zhang, C.; Liu, Y.; Ye, S.; Zhou, D.; Blackman, R.K.; et al. Synergistic activity of the Hsp90 inhibitor ganetespib with taxanes in non-small cell lung cancer models. Invest. New Drugs 2012, 30, 2201-2209. [CrossRef] [PubMed]

19. Wang, Y.; Liu, H.; Diao, L.; Potter, A.; Zhang, J.; Qiao, Y.; Wang, J.; Proia, D.A.; Tailor, R.; Komaki, R.; et al. Hsp90 Inhibitor Ganetespib Sensitizes Non-Small Cell Lung Cancer to Radiation but Has Variable Effects with Chemoradiation. Clin. Cancer Res. 2016, 22, 5876-5886. [CrossRef]

20. Smith, D.L.; Acquaviva, J.; Sequeira, M.; Jimenez, J.P.; Zhang, C.; Sang, J.; Bates, R.C.; Proia, D.A. The HSP90 inhibitor ganetespib potentiates the antitumor activity of EGFR tyrosine kinase inhibition in mutant and wild-type non-small cell lung cancer. Target. Oncol. 2015, 10, 235-245. [CrossRef]

21. Sang, J.; Acquaviva, J.; Friedland, J.C.; Smith, D.L.; Sequeira, M.; Zhang, C.; Jiang, Q.; Xue, L.; Lovly, C.M.; Jimenez, J.P.; et al. Targeted inhibition of the molecular chaperone Hsp90 overcomes ALK inhibitor resistance in non-small cell lung cancer. Cancer Discov. 2013, 3, 430-443. [CrossRef] [PubMed]

22. Akram, A.; Khalil, S.; Halim, S.A.; Younas, H.; Iqbal, S.; Mehar, S. Therapeutic Uses of HSP90 Inhibitors in Non-Small Cell Lung Carcinoma (NSCLC). Curr. Drug. Metab. 2018, 19, 335-341. [CrossRef] [PubMed]

23. Prodromou, C.; Roe, S.M.; O’Brien, R.; Ladbury, J.E.; Piper, P.W.; Pearl, L.H. Identification and structural characterization of the ATP / ADP-binding site in the Hsp90 molecular chaperone. Cell 1997, 90, 65-75. [CrossRef]

24. Ehrlich, E.S.; Wang, T.; Luo, K.; Xiao, Z.; Niewiadomska, A.M.; Martinez, T.; Xu, W.; Neckers, L.; Yu, X.F. Regulation of Hsp90 client proteins by a Cullin5-RING E3 ubiquitin ligase. Proc. Natl. Acad. Sci. USA 2009, 106, 20330-20335. [CrossRef]

25. Sequist, L.V.; Gettinger, S.; Senzer, N.N.; Martins, R.G.; Janne, P.A.; Lilenbaum, R.; Gray, J.E.; Iafrate, A.J.; Katayama, R.; Hafeez, N.; et al. Activity of IPI-504, a novel heat-shock protein 90 inhibitor, in patients with molecularly defined non-small-cell lung cancer. J. Clin. Oncol. 2010, 28, 4953-4960. [CrossRef] [PubMed]

26. Sessa, C.; Shapiro, G.I.; Bhalla, K.N.; Britten, C.; Jacks, K.S.; Mita, M.; Papadimitrakopoulou, V.; Pluard, T.; Samuel, T.A.; Akimov, M.; et al. First-in-human phase I dose-escalation study of the HSP90 inhibitor AUY922 in patients with advanced solid tumors. Clin. Cancer Res. 2013, 19, 3671-3680. [CrossRef]

27. Felip, E.; Barlesi, F.; Besse, B.; Chu, Q.; Gandhi, L.; Kim, S.W.; Carcereny, E.; Sequist, L.V.; Brunsvig, P.; Chouaid, C.; et al. Phase 2 Study of the HSP-90 Inhibitor AUY922 in Previously Treated and Molecularly Defined Patients with Advanced Non-Small Cell Lung Cancer. J. Thorac. Oncol. 2018, 13, 576-584. [CrossRef] [PubMed]

28. Johnson, M.L.; Yu, H.A.; Hart, E.M.; Weitner, B.B.; Rademaker, A.W.; Patel, J.D.; Kris, M.G.; Riely, G.J. Phase I/II Study of HSP90 Inhibitor AUY922 and Erlotinib for EGFR-Mutant Lung Cancer With Acquired Resistance to Epidermal Growth Factor Receptor Tyrosine Kinase Inhibitors. J. Clin. Oncol. 2015, 33, 1666-1673. [CrossRef] [PubMed]

29. Ramalingam, S.; Goss, G.; Rosell, R.; Schmid-Bindert, G.; Zaric, B.; Andric, Z.; Bondarenko, I.; Komov, D.; Ceric, T.; Khuri, F.; et al. A randomized phase II study of ganetespib, a heat shock protein 90 inhibitor, in combination with docetaxel in second-line therapy of advanced non-small cell lung cancer (GALAXY-1). Ann. Oncol. 2015, 26, 1741-1748. [CrossRef] 
30. Pillai, R.N.; Fennell, D.A.; Kovcin, V.; Ciuleanu, T.E.; Ramlau, R.; Kowalski, D.; Schenker, M.; Yalcin, I.; Teofilovici, F.; Vukovic, V.M.; et al. Randomized Phase III Study of Ganetespib, a Heat Shock Protein 90 Inhibitor, With Docetaxel Versus Docetaxel in Advanced Non-Small-Cell Lung Cancer (GALAXY-2). J. Clin. Oncol. 2020, 38, 613-622. [CrossRef]

31. Socinski, M.A.; Goldman, J.; El-Hariry, I.; Koczywas, M.; Vukovic, V.; Horn, L.; Paschold, E.; Salgia, R.; West, H.; Sequist, L.V.; et al. A multicenter phase II study of ganetespib monotherapy in patients with genotypically defined advanced non-small cell lung cancer. Clin. Cancer Res. 2013, 19, 3068-3077. [CrossRef]

32. Rong, B.; Yang, S. Molecular mechanism and targeted therapy of Hsp90 involved in lung cancer: New discoveries and developments (Review). Int. J. Oncol. 2018, 52, 321-336. [CrossRef]

33. Voruganti, S.; Kline, J.T.; Balch, M.J.; Rogers, J.; Matts, R.L.; Hartson, S.D. Proteomic Profiling of Hsp90 Inhibitors. Methods Mol. Biol. 2018, 1709, 139-162.

34. Zimmer, A.; Amar-Farkash, S.; Danon, T.; Alon, U. Dynamic proteomics reveals bimodal protein dynamics of cancer cells in response to HSP90 inhibitor. BMC Syst. Biol. 2017, 11, 33. [CrossRef] [PubMed]

35. Marrugal, Á.; Ferrer, I.; Pastor, M.D.; Ojeda, L.; Quintanal-Villalonga, Á.; Carnero, A.; Molina-Pinelo, S.; Paz-Ares, L. Impact of Heat Shock Protein 90 Inhibition on the Proteomic Profile of Lung Adenocarcinoma as Measured by Two-Dimensional Electrophoresis Coupled with Mass Spectrometry. Cells 2019, 8, 806. [CrossRef] [PubMed]

36. Weidenauer, L.; Wang, T.; Joshi, S.; Chiosis, G.; Quadroni, M.R. Proteomic interrogation of HSP90 and insights for medical research. Expert Rev. Proteomics 2017, 14, 1105-1117. [CrossRef] [PubMed]

37. Chatterjee, S.; Bhattacharya, S.; Socinski, M.A.; Burns, T.F. HSP90 inhibitors in lung cancer: Promise still unfulfilled. Clin. Adv. Hematol. Oncol. 2016, 14, 346-356.

38. Mishra, D.; Banerjee, D. Lactate Dehydrogenases as Metabolic Links between Tumor and Stroma in the Tumor Microenvironment. Cancers (Basel) 2019, 11, 750. [CrossRef] [PubMed]

39. Dennison, J.B.; Molina, J.R.; Mitra, S.; Gonzalez-Angulo, A.M.; Balko, J.M.; Kuba, M.G.; Sanders, M.E.; Pinto, J.A.; Gomez, H.L.; Arteaga, C.L.; et al. Lactate dehydrogenase B: A metabolic marker of response to neoadjuvant chemotherapy in breast cancer. Clin. Cancer Res. 2013, 19, 3703-3713. [CrossRef] [PubMed]

40. McCleland, M.L.; Adler, A.S.; Deming, L.; Cosino, E.; Lee, L.; Blackwood, E.M.; Solon, M.; Tao, J.; Li, L.; Shames, D.; et al. Lactate dehydrogenase $\mathrm{B}$ is required for the growth of KRAS-dependent lung adenocarcinomas. Clin. Cancer Res. 2013, 19, 773-784. [CrossRef]

41. Hou, G.X.; Liu, P.; Yang, J.; Wen, S. Mining expression and prognosis of topoisomerase isoforms in non-small-cell lung cancer by using Oncomine and Kaplan-Meier plotter. PLoS ONE 2017, 12, e0174515. [CrossRef] [PubMed]

42. Lu, B.; Zhang, H.; Zhang, T.; Cai, Y.; Hu, Y.; Zheng, H.; Li, B. Topoisomerase I expression is associated with prognosis in postoperative non-small cell lung cancer patients. Thorac. Cancer 2016, 7, 486-494. [CrossRef] [PubMed]

43. Riedlinger, T.; Bartkuhn, M.; Zimmermann, T.; Hake, S.B.; Nist, A.; Stiewe, T.; Kracht, M.; Schmitz, M.L. Chemotherapeutic Drugs Inhibiting Topoisomerase 1 Activity Impede Cytokine-Induced and NF-kappaB p65-Regulated Gene Expression. Cancers (Basel) 2019, 11, 883. [CrossRef] [PubMed]

44. Serman, L.; Nikuseva Martic, T.; Serman, A.; Vranic, S. Epigenetic alterations of the Wnt signaling pathway in cancer: A mini review. Bosn. J. Basic Med. Sci. 2014, 14, 191-194. [CrossRef] [PubMed]

45. Chen, X.; Song, X.; Yue, W.; Chen, D.; Yu, J.; Yao, Z.; Zhang, L. Fibulin-5 inhibits Wnt/beta-catenin signaling in lung cancer. Oncotarget 2015, 6, 15022-15034. [CrossRef] [PubMed]

46. Remmelink, M.; Mijatovic, T.; Gustin, A.; Mathieu, A.; Rombaut, K.; Kiss, R.; Salmon, I.; Decaestecker, C. Identification by means of cDNA microarray analyses of gene expression modifications in squamous non-small cell lung cancers as compared to normal bronchial epithelial tissue. Int. J. Oncol. 2005, 26, 247-258. [CrossRef] [PubMed]

47. Iwagami, Y.; Eguchi, H.; Nagano, H.; Akita, H.; Hama, N.; Wada, H.; Kawamoto, K.; Kobayashi, S.; Tomokuni, A.; Tomimaru, Y.; et al. miR-320c regulates gemcitabine-resistance in pancreatic cancer via SMARCC1. Br. J. Cancer 2013, 109, 502-511. [CrossRef]

48. Li, Q.Q.; Hao, J.J.; Zhang, Z.; Krane, L.S.; Hammerich, K.H.; Sanford, T.; Trepel, J.B.; Neckers, L.; Agarwal, P.K. Proteomic analysis of proteome and histone post-translational modifications in heat shock protein 90 inhibition-mediated bladder cancer therapeutics. Sci. Rep. 2017, 7, 201. [CrossRef] [PubMed]

49. Gigek, C.O.; Lisboa, L.C.; Leal, M.F.; Silva, P.N.; Lima, E.M.; Khayat, A.S.; Assumpcao, P.P.; Burbano, R.R.; Smith Mde, A. SMARCA5 methylation and expression in gastric cancer. Cancer Invest. 2011, 29, 162-166. [CrossRef]

50. Jin, Q.; Mao, X.; Li, B.; Guan, S.; Yao, F.; Jin, F. Overexpression of SMARCA5 correlates with cell proliferation and migration in breast cancer. Tumour. Biol. 2015, 36, 1895-1902. [CrossRef]

51. Ribeyre, C.; Zellweger, R.; Chauvin, M.; Bec, N.; Larroque, C.; Lopes, M.; Constantinou, A. Nascent DNA Proteomics Reveals a Chromatin Remodeler Required for Topoisomerase I Loading at Replication Forks. Cell Rep. 2016, 15, 300-309. [CrossRef]

52. Ito, H.; Morishita, R.; Nagata, K.I. Functions of Rhotekin, an Effector of Rho GTPase, and Its Binding Partners in Mammals. Int J. Mol. Sci. 2018, 19, 2121. [CrossRef] [PubMed]

53. Bishop, A.L.; Hall, A. Rho GTPases and their effector proteins. Biochem. J. 2000, 348, 241-255. [CrossRef]

54. Memmel, S.; Sisario, D.; Zoller, C.; Fiedler, V.; Katzer, A.; Heiden, R.; Becker, N.; Eing, L.; Ferreira, F.L.R.; Zimmermann, H.; et al. Migration pattern, actin cytoskeleton organization and response to PI3K-, mTOR-, and Hsp90-inhibition of glioblastoma cells with different invasive capacities. Oncotarget 2017, 8, 45298-45310. [CrossRef] 
55. Lopez, L.C.; Schuelke, M.; Quinzii, C.M.; Kanki, T.; Rodenburg, R.J.; Naini, A.; Dimauro, S.; Hirano, M. Leigh syndrome with nephropathy and CoQ10 deficiency due to decaprenyl diphosphate synthase subunit 2 (PDSS2) mutations. Am. J. Hum. Genet. 2006, 79, 1125-1129. [CrossRef]

56. Chen, P.; Yu, J.; Knecht, J.; Chen, Q. Decrease of PDSS2 expression, a novel tumor suppressor, in non-small cell lung cancer. Cancer. Epidemiol. 2013, 37, 166-171. [CrossRef] [PubMed]

57. Chen, P.; Zhang, Y.; Polireddy, K.; Chen, Q. The tumor-suppressing activity of the prenyl diphosphate synthase subunit 2 gene in lung cancer cells. Anticancer Drugs 2014, 25, 790-798. [CrossRef] [PubMed]

58. Brea-Calvo, G.; Rodriguez-Hernandez, A.; Fernandez-Ayala, D.J.; Navas, P.; Sanchez-Alcazar, J.A. Chemotherapy induces an increase in coenzyme Q10 levels in cancer cell lines. Free Radic. Biol. Med. 2006, 40, 1293-1302. [CrossRef]

59. HSP90 Interactors. Available online: https:/ / www.picard.ch/downloads/Hsp90interactors.pdf (accessed on 20 May 2020).

60. Jahani, M.; Noroznezhad, F.; Mansouri, K. Arginine: Challenges and opportunities of this two-faced molecule in cancer therapy. Biomed. Pharmacother. 2018, 102, 594-601. [CrossRef] [PubMed]

61. Keshet, R.; Erez, A. Arginine and the metabolic regulation of nitric oxide synthesis in cancer. Dis. Model. Mech 2018, 11. [CrossRef]

62. Lee, Y.J.; Galoforo, S.S.; Berns, C.M.; Chen, J.C.; Davis, B.H.; Sim, J.E.; Corry, P.M.; Spitz, D.R. Glucose deprivation-induced cytotoxicity and alterations in mitogen-activated protein kinase activation are mediated by oxidative stress in multidrug-resistant human breast carcinoma cells. J. Biol. Chem. 1998, 273, 5294-5299. [CrossRef] [PubMed]

63. Joly, J.H.; Delfarah, A.; Phung, P.S.; Parrish, S.; Graham, N.A. A synthetic lethal drug combination mimics glucose deprivationinduced cancer cell death in the presence of glucose. J. Biol. Chem. 2020, 295, 1350-1365. [CrossRef] [PubMed]

64. Simons, A.L.; Mattson, D.M.; Dornfeld, K.; Spitz, D.R. Glucose deprivation-induced metabolic oxidative stress and cancer therapy. J. Cancer Res. Ther. 2009, 5, S2-S6. [PubMed] 